\title{
Al-Enhanced Business Models for Digital Entrepreneurship
}

\author{
Wolfgang Pfau and Philipp Rimpp
}

\section{Abstract}

The world of AI offers new opportunities for companies and is therefore of particular interest to entrepreneurs at potentially every level impacting their business. The following article therefore tries to classify the roles of artificial intelligence (AI) applications on the strategic level and their influence on business models. By means of case studies, current business practice will be examined to give entrepreneurs and researchers an understanding of this technology, by providing practical examples so that they can pursue their own AI path. The analysis is based on case studies that examine the role of AI in a company's business model, both for new market participants in the form of start-ups and incumbents such as the tech giants. By means of case studies, both sides of the extremes are covered in order to provide a picture of the scope of the applications. Insights from these case studies are processed to develop a classification scheme of the influence of AI on business models. Furthermore, the interaction of the different innovation possibilities of AI is compared and with that the importance for the innovative power of companies. Additionally, strategy types are developed on the basis of the presented classification scheme, but give entrepreneurs a suggestion for their own AI path in terms of AI applications to consider. Further, research could consider the influence of the presented AI roles in business models, especially the AI-driven business model is of interest here.

W. Pfau · P. Rimpp $(\bowtie)$

Clausthal University of Technology, Clausthal-Zellerfeld, Germany

e-mail: philipp.rimpp@tu-clausthal.de 


\section{The Relevance of Al for Digital Entrepreneurs}

The technology of artificial intelligence (AI) is already considered to be a ground-breaking technology that has the potential to fundamentally change markets, industries and in general business activities. Its disruption and innovation potential is considered to be of a magnitude that cannot be compared to any known technology. And yet the threshold for research and use of AI is still ongoing (cf. Marr and Ward 2019, pp. 1-3). This opens the opportunity to participate in this pioneering technology and make it available for usage by entrepreneurs at every market level. At the same time, this also increases the pressure not to fall behind. For entrepreneurs as well as companies the question arises as to how much influence AI can have on their business now and in the future and how they can leverage the technological potential for themselves. Against this background, it is essential that entrepreneurs consider the consequences of AI in their business model.

AI technology is not a new phenomenon, neither in science nor for companies. However, recent developments, e.g. in machine learning (ML), lead to breakthroughs in the applicability of AI in many areas. These changes and improvements in usability now allow many companies to use this technology in various applications.

The idea that AI is not yet or only to a small extent present in the entrepreneurial world and that it is rather a theoretically phenomenon would be a misconception that an entrepreneur could succumb to. In fact, AI or algorithms that come close to it have already penetrated many areas of everyday life. Many of these examples are currently familiar to users, while others often remain hidden. Examples are shopping suggestions, face recognition or speech assistants (cf. Intel Corporation 2020). Some voices even go a step further and speak of a new age of AI, in which human abilities and talents are challenged by AI, thus changing the question of the long-term changes in human life, including in the corporate and new venture sector (cf. Iansiti and Lakhani 2020, pp. 17-18). Due to the fact, that AI is already used in many and diverse areas, the question arises how this technology can influence the business and especially the business model (BM) of an entrepreneur. Furthermore, the use of AI naturally requires technological investments and access to the relevant data for the operating of AI. In particular, the output quality of AI depends on the quality and quantity of available data (cf. Agrawal et al. 2018, pp. 98-99).

All these developments illustrate not only the potential, but also the already dominant influence and opportunities that AI can offer companies. From this point of view, it is of interest for entrepreneurs to know what general possibilities are available to them. Especially the effects on a strategic level more precisely the innovation of the business model through AI applications are the focus of this article. Finally, the range of innovation possibilities shall be shown so that entrepreneurs become aware of this potential and can use it. 


\section{Theoretical Background for Entrepreneurs}

\subsection{The Technological Aspect of Al}

A unitary definition of artificial intelligence (AI), and thus when it can be attributed to a machine, has so far been omitted because it differs according to the point of view. Essentially, the approaches to definition differ in their determination of intelligence, how this intelligence manifests itself and at what point a machine can be considered intelligent (cf. Legg and Hunter 2007, pp. 7-8).

Nevertheless, it is possible to distinguish two forms of AI that are generally different in the way these programs work. First, the symbolic AI is a learning program that focuses on symbols as operating ground for its learning progress. A rule-based thinking presented in the symbols, e.g. numbers, drives this form. The major advantage of this type of artificial intelligence is its practicability for the human users. Because its logic is quite easy to understand for a human, it can be useful as a support system. This may provide a user or company with an advantage over another non-user, if used correctly. Their potential often lies in the automation of processes, which are usually consuming intense amounts of time and knowledge. On the other hand, the symbolic AI is a program that needs a lot of programming work done into it. This is why the symbolic AI gets quite expensive (cf. Lee et al. 2019, pp. 2-3). The other major form of intelligence is the so-called neural AI, which is enabled by the usage of machine learning. This method uses algorithm of improved learning by using practice or sample data as learning material for generating patterns that it can later rely upon. The goal of this method is that the AI should function like a human brain, in the sense that even complex problems can be solved, similar to neural work. Thus, neural AI is not needing actual training embraced by humans in the form of teachers. Its objective is to learn by itself from data sources it is given access to (cf. Lee et al. 2019, p. 4). Especially, ML and its subfield deep learning are known from this area, due to major breakthroughs of these research fields especially in the field of image and voice processing (cf. Skilton and Hovsepian 2018, pp. 132-134). This field is receiving more and more attention from researchers and companies, because it has the potential to learn from raw data. Conversely, this means that less human work has to be done in advance. While both methods or types of AI still face problems in terms of scalability and reasoning, much hope is put into the combination of both types. The combination creates the hope of solving tasks related to fundamental problems in the applicability of the technology. Examples of these challenges are insufficient data for operations or the solution of the black-box appearance of AI to a human observer. While this research stream is still in its infancy, entrepreneurs should pay attention to future opportunities (cf. Lee et al. 2019, pp. 4-5).

Beyond the basic understanding of how AI can be differentiated from a technological view, it is important for the entrepreneur, to know what AI can do for his or her business. An approach to understand the way AI works in the practical context is to understand it as a prediction machine. This logic focuses on the very 
basic principle of an AI output. If $\mathrm{AI}$ is used, it is trained in advance based on data. In the subsequent application, the AI uses its learning chains to evaluate the situation it is to consider. This process is described as prediction, as the AI uses given data to indicate the missing information. Therefore, this technology cannot only make statements about current problems, but also about past and future. This of course requires that the AI has a sufficient amount of data (cf. Agrawal et al. 2018, pp. 23-30). This brief overview of the technical background and the practicable interpretation of AI show that entrepreneurs should have at least a superficial knowledge of the technology when using it or even considering to use it in the future.

\subsection{The (Current) Role of Al in Developing Business Models}

Given the research approaches to AI and entrepreneurship, a variety of paths can be identified. In the sense of this article, the primary goal is to identify the effects of AI on a strategic corporate level. This is accompanied by an examination of the business model and the effects on it. There are also numerous research streams and definitions for the business model. At this point, the business model definition of Osterwalder and Pigeur, who define it as the "rationale of how an organization creates, delivers and captures value" (Osterwalder and Pigneur 2010, p. 14), will be used as a basis for continuing research here. Furthermore, the effects of the use of AI on the business model will be examined, especially in its effects on the business model canvas.

The world of business models under the influence of AI is not a new research phenomenon but has already received some attention. On the one hand, research has already been conducted on the influence of AI applications on the individual elements of the business model (cf. Metelskaia et al. 2018, pp. 38-40). Such comprehensive views open up the possibility for the entrepreneur to estimate which influences they can use for their own innovation of the business model. On the other hand, there are already approaches for long-term planning of the integration of AI into the company. Such strategic developments are fossilized on a path that the company takes to integrate AI applications into its own business. Examples for such planning methods can be general plans for the adaptation of AI applications in the company (cf. Rao 2017, pp. 9-10), or portfolio planning like the 3 Horizon framework for AI (cf. Kreutzer and Sirrenberg 2020, pp. 235-238). In the area of these planning methods and procedures, there are various examples of literature on this topic. It can therefore be concluded that the current role of AI in the development of business models is limited to their influence on the elements and their planning for future business models. However, an important question, regarding AI as a technology in general, which both views tend to neglect, is still lingering. The question of methodologies is determining the strategic direction of AI applications and their impact on business models. This includes how AI applications influence business models through innovation, respectively, implementation. This is accompanied by the role of AI in the innovation of the business model, independent 
of the desired state or form of the business model. In this way, it should be clarified for entrepreneurs how these AI applications can be differentiated from a strategic perspective in order to be able to shape their visions by means of the corresponding AI performance in the business model. A study of the business world is therefore necessary at this point.

\subsection{Method of Investigation}

For the exploration of the current and partly future use of AI applications in the business context, the first question is how this should be investigated. In the context of this chapter, an attempt is made to give a picture of the landscape of AI use in the entrepreneurial context. Especially the effects on a strategic level are of interest. For this to happen within a certain framework, a limitation is necessary. The range of enterprises and the related examples of use are numerous in the real world. From innovative start-ups to medium-sized companies and large incumbents, a broad spectrum is opening that presents a challenge. Therefore, the research approach is divided into two parts. First, start-ups are to be investigated and thus how these firms design AI applications and make them available to the market. In the second part, established, preferably innovative companies will be examined, which have a clear focus on AI solutions and, if possible, show a broad range of applications. This should not only show which application possibilities are already established and therefore practicable, but also which possibilities exist for companies that want to acquire them. Furthermore, this will be done with a focus on explorative case studies, which will be able to give an insight into the use of the technology (cf. Siggelkow 2007, pp. 20-23). Subsequently, the usage and especially the strategic possibilities for innovation through AI will be shown. All this is done in the context of the business model and its innovation. A connection to the business model should therefore be considered at every point.

Table 1 Strategies for AI applications

\begin{tabular}{l|l|l|l|l}
\hline & Outsourcing & Incremental & Profound & Disruptor \\
\hline $\begin{array}{l}\text { Performance/ } \\
\text { Awareness }\end{array}$ & Common & Standard & Unique/Unrivalled & Unchallenged \\
\hline Development & Outsourcing & Outsourcing/In-house-development & In-house-development & In-house-development \\
\hline $\begin{array}{l}\text { Change } \\
\text { potential }\end{array}$ & Minor & Minor-moderate & Moderate-Profound & Profound-disruptive \\
$\begin{array}{l}\text { Type of } \\
\text { business } \\
\text { model } \\
\text { innovation }\end{array}$ & Support & Support & Support/Driver & Driver \\
\hline
\end{tabular}




\section{Development of a Schema from Practice}

When analysing start-ups in the AI field, it can be quickly determined that a wide range of existing companies with very different focuses on the application of AI prevails. Therefore, a narrowing down is mandatory. First, the scope of applications of AI should be narrowed down. For a fundamental examination of the influence of AI services on business models, it is particularly useful to focus on core elements of the organization. This means that the applications should be as independent as possible from the industry sector in which a company is active. On the other hand, existing market services which are already established and thus available to as many user companies as possible are of interest. At the same time, the effects of such a start up on the market, in terms of changes to the business model, are to be investigated. This means that not only the elements of the business model canvas that would be changed by such a service should be identified, but also the role of innovation that the change would bring. Due to the large number of start-ups in the AI field, a further narrowing down is necessary here as well. At this point, the research approach will concentrate on companies in the German area (cf. Table 2: References of AI start-ups).

The limited investigation of the German start-up world in the field of AI reveals several indications. First, the companies appear as providers of AI software and usually market it as AI-as-a-Service (AIaaS), based on the business models of the software-as-a-service industry. An AIaaS provider is thus a vendor of a finished and usable product or service that is made available to the customer by the provider, for regular payment (Metelskaia et al. 2018, p. 36). In this way, AI becomes a product on which a company builds its business model and brings their type of AI to market. The path away from a per-seat model to a model of utilization is already clearly recognizable or predominant in the area of AIaaS in the cases considered here. Additionally, the role of AI for the user of these AIaaS products can be defined in terms of their impacts on the BM. First assisting functions and supporting functions as the following can be identified.

AI-assisted: Business processes that are improved or supported by AI, but do not directly contribute to strategic elements and therefore do not affect any element of the business model. The focus remains on operational tasks.

AI-supported: AI services that directly influence one or more elements of a company's business model and modify it without fundamentally changing the established business model.

While these definitions give an understanding about the strategic impact on the lower end of the BM spectrum, further research on major impacting roles should be made. Those impactful AI services/roles are to be identified in real-world examples.

Furthermore, clear differences can be identified in the target applications of the AI, which relate to the core functions of the company. A distinction can be made here between applications that focus on the company's own activities and those that focus on customer-specific activities. Company activities refer to the way the company carries out activities, such as partnerships or cost structures. On the other 
hand, customer-specific activities which focus on activities related to the customer, such as communication or channels. This differentiation in two directions of the influence of an AI service allows a classification for the company, when considering it. Of course, not every AI application is equally influential in terms of its orientation and impact. Furthermore, a differentiation regarding the direction of orientation also suggests that one or both directions can be present simultaneously to varying degrees. This means that a distinction can be made regarding the influence. Applications that have no influence on an orientation side would be listed accordingly in this scheme on the zero line of the axis. The classification of such an application will be illustrated by the following figure (Fig. 1).

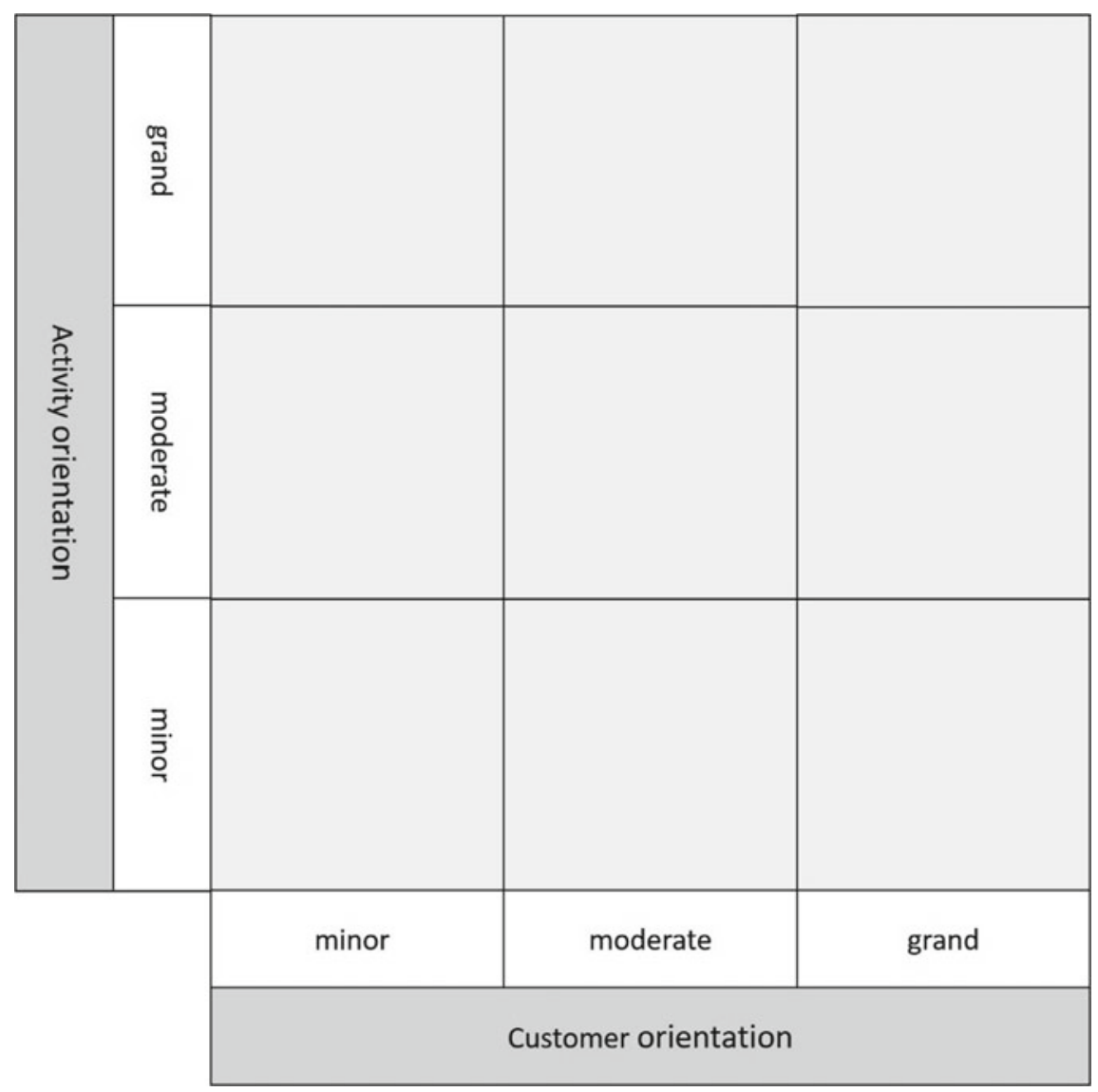

Fig. 1 Classification scheme for AI applications 
For additional illustration of this classification scheme, the following case studies serve as examples in their usage of AI applications. Moreover, additional investigations in this chapter are to be made based on the classification scheme.

\section{Examples from Practice: Investigating Newcomers and Incumbent Enterprises}

\subsection{Illustrating a Newcomer: The Case of E-Bot7}

The German company of e-bot7 is a start-up founded in mid-2016 and located in the city of Munich. The product the company is offering is based around an AI-driven algorithm that is oriented towards automated customer response communication. It is offering its customers the reduction of employee usage in customer communication through the usage of their algorithm. This is achieved by an NLP algorithm, that is not only learning on given use cases of customer contact, but also constantly evolving due to ongoing business cases (cf. e-bot7 2020a). It aims at automated responses to standardized customer questions and the sorting of more complex queries to the expected professional in between the company. Their product the Agent $+\mathrm{KI}^{\circledR} \mathrm{Hybrid}$ Model is confirming the correctness of given answers by being trained through the employees of the operating company. That way the purchaser of e-bot7 AI-based product can train the algorithm for their service operations (cf. e-bot7 2020b). At best automated answers can be generated to handle repeating and uncomplicated questions. For the purchaser, this can enable the employees to focus on more complex customer questions and the preserving of labour that can be automated. Moreover, that way the operating company shall be getting an advantage by a less cost-intensive customer care service. Customers of the e-bot7 products are well-known company's like Deutsche Bahn or O2 (cf. DIA Group B.V. 2020). The case of e-bot7 clearly shows a business model as AIaaS provider. The product a customized AI for customer communication with its promised human needed labour through automation is thereby the value proposition of the business model. On the other hand, the usage of the product of e-bot7s by a company within their business model can rather be classified as AI-supported. In relation to the classification scheme presented above, the AI focuses on customer communication and thus a customer orientation that has a (potentially) moderate degree of intensity. On the activity side of the scheme, however, it can be assumed that the more cost-oriented and personnel-reducing activities of the AI have a minor inflow. This is particularly given by the possible automation of communication.

\subsection{Incumbents Innovation Through Al: Case Studies from Amazon}

Amazon is serving as the first case study of an incumbent, consisting of three examples, on how Amazon uses AI in different ways for different objectives in 
between their company structure. As a first example, Amazon Web Services is a product and service platform for Internet-based technologies that Amazon offers its customers. The range of services offered extends from analytical services, blockchain, databases and storage to tools for developers (cf. Amazon.com Inc. 2020a). Against the background of this study, the machine learning offer is of interest. With this service, Amazon offers its customers the possibility of AI applications. At this point, this means that Amazon offers the infrastructure and the service of development and thus provides the customers the possibility to develop AI services at lower costs. These costs can not only be of a direct monetary nature but can also be reflected in the personnel area. By that companies using this offer need less personnel with the skills in machine learning or AI to carry out their own developments in this area. Thus, this service from Amazon Web Services is not only to be understood as an Infrastructure-as-a-Service but also as an AI-as-a-Service. Secondly, Amazon Go and Amazon Go Grocery should serve as another example for the use of AI. This represents a separate mainstay of Amazon in the grocery retail sector. The essential concept of this store model is the shopping experience without queues at the checkout. This is achieved by dispensing the physical checkout. This so-called checkout-free shopping is attained by using AI to record the products taken by the customer. By the aid of sensors, the AI can monitor the status of the products in the market permanently. When the customer leaves the shop, an invoice is automatically sent to the Amazon customer's account (cf. Amazon.com Inc. 2020b). With the use of the AI, a value creation for the customer is operated in this BM. The transaction costs for the customer are minimized by the elimination of the checkout. This not only improves customer service, but also creates a completely new value creation service (cf. Clickatell Inc. 2020). On the other hand, this BM also changes the usual structure of the shop operator. By using AI, personnel costs for the checkout are omitted. Furthermore, this $\mathrm{BM}$ is only made possible by using AI. It represents the fundamental component that not only makes the innovation of the BM possible, but also operates this model. The business model can therefore be described as AI-driven. Additionally, the orientation in terms of the BM is to be considered moderate to grand on both sides. As a final example, the concept of anticipatory shipping has to be mentioned. Amazon has been thinking about radically changing its retail business model with the use of AI and has even patented this (cf. Google Patents 2012). Under the term "anticipatory shipping", the company developed an idea where the shipping of a product should take place before the actual sale. Based on the prediction of an AI, products that are expected to be desired by the customer should be shipped without their order. Subsequently, the customers could then decide whether to return or keep the product. There are different interpretations of whether the product should be shifted anticipatory into a closer environment or delivered directly to the customer (cf. On Marketing 2014), (cf. Lomas 2014). Regardless of the interpretation of such a model, it shows a phenomenon in the way Amazon would change the way it does business. The customer would no longer be the sole executor of a purchase, but the AI would also. The arguments for such a drastic change of the BM are in the way the value creation should take place after the change. It is assumed that value is created for the customer by taking over the activity of selecting and buying. This is intended to relieve the burden on the customer and at 
the same time strengthen the relationship with the company. It is also assumed that such an innovation of the BM would have an impact on all areas of the BM (cf. Agrawal et al. 2018, pp. 16-17). Ultimately, it is essential for the context considered here that the AI would make the new business model possible in the first place. The execution and efficiency of the prediction of the AI used thus determine the business activities, and therefore, such a business model can be considered AI-driven. Furthermore, such a BM innovation would be a significant change in the market. In the context of innovation categorization, this could certainly become out as a disruptive $\mathrm{BM}$ and the orientation would be grand in each side of the orientation.

\subsection{Incumbents Innovation Through Al: Case Studies from Uber}

The first case of AI used by Uber is the company's own AI platform Michelangelo. It enables the internal teams of Uber machine learning to use it in a scalable way. This means that Uber provides itself with an AI platform so that all developers and designers in the company have a uniform infrastructure for their development projects. Through this unified infrastructure, all participants should have the same development opportunities, an ability to grow the AI projects in the company and also a cost-saving is achieved through the standardization. With this, Uber has created a service to support own processes in the company (cf. Hermann 2017). The service can be seen as AIaaS and developed by the company for the own company. From the user's point of view, it is a support of the development processes and is therefore not a core element of the BM. Rather, it assists in the development of potentially supporting or value-adding AI services in the future. Thus, the AI platform can be classified as AI-assisted and has an internal focus, in the context of innovations through AI. The second case study at Uber is about Uber Marketplace, which is intended to illustrate the use of AI within this business form. Uber Marketplace is a platform where passengers and drivers are brought together. Uber acts here as an intermediary between both parties, for a fee. In this platform business model Uber has integrated AI to improve the platform's own performance. With the help of AI, the usage behaviour of customers is predicted in order to achieve the capacity utilization of the drivers on the one side and the optimal provision of trips for the customer on the other side. The use and integration of the AI into the platform model enable the company to offer its own services more efficiently and at the same time maximize the benefit for the customer by ensuring the highest possible reliability. While it can be assumed that the value creation has the same goal as before and is strengthened if possible, this AI use achieves a mutual focus on both the company and the customer side (cf. Uber 2020). In the context of the classification of AI performance for the business model, it is therefore to be described as AI-supported. The impact on the business model can be described as moderate in both directions of the classification scheme at this point. However, by focusing on both halves of the business model, the value creation is possibly increased. 


\section{Implications for Practice}

\subsection{Differentiation of the Effects of Innovation}

The preceding case studies not only distinguish the AI's rollers in terms of potential assisting or supporting services for the business model, but also showed the driving potential of these within a BM. The Amazon case shows here in two different configurations that AI-driven business models can be theoretically and practically possible, or that this is already established. The possibility of such a business model based on the performance of the AI turned out to be new business models on the market in the two cases presented here.

Nevertheless, there is a certain hierarchy with concerning the improvement of business models with AI. As a basis, the Infrastructure-as-a-Service or the AI-as-a-Service is shown. The infrastructure is necessary for self-development while AIaaS allows the direct use or implementation of AI. One of the two services is therefore necessary to make AI usable in any form for the BM. The previous definitions are in line with this within their potential of influence, starting from the assisting to the supporting service to the driving factor, the influence of the AI on the business model increases. The extent cannot be scaled at this point, as it depends on the practical design of the BM. Nevertheless, such a dimensioning of the influence can be shown. All this is of course done in the context of an improvement of BM by means of AI. Thus, the entrepreneur has the choice of the role of the AI from the options presented here for the enhancement of his own business model (Fig. 2).

\begin{tabular}{|c|c|c|}
\hline \multicolumn{3}{|c|}{ Al-enhanced } \\
\hline $\begin{array}{l}\text { Al-assisted: } \\
\text { Business processes that } \\
\text { are improved or } \\
\text { supported by Al, but do } \\
\text { not directly contribute } \\
\text { to strategic elements } \\
\text { and therefore do not } \\
\text { affect any element of } \\
\text { the business model. } \\
\text { The focus remains on } \\
\text { operational tasks. }\end{array}$ & \begin{tabular}{l}
\multicolumn{2}{c}{ Al-supported: } \\
Al services that directly \\
influence one or more \\
elements of a \\
company's business \\
model and modify it \\
without fundamentally \\
changing r the \\
established business \\
model.
\end{tabular} & $\begin{array}{l}\text { Al-driven: } \\
\text { Al services that enable } \\
\text { the introduction and } \\
\text { performance of a new } \\
\text { type of business model. } \\
\text { A key factor is the } \\
\text { necessity of the Al to } \\
\text { drive the business } \\
\text { model. }\end{array}$ \\
\hline
\end{tabular}

Fig. 2 Roles of AI in enhancing the business model 
Furthermore, the case studies carried out can be prescribed within the "innovation matrix". The cases here illustrate the scope of AI applications on a strategic level. Not only one-sided fossilized application possibilities, but also double-sided, partly varyingly pronounced combinations are possible.

In addition, it has been shown that AI cannot only be developed in-house but is also available to companies in the form of market services. Noticeably, not every conceivable form of AI for companies is available on the market, but many functions are already offered that can be related to core functions of a company. Nevertheless, there are already providers who offer development assistance with their services for AI-based services. The offers on shown here are mostly AIaaS and play an assisting or supporting role the user organizations. These applications have an innovative character, which can have a moderate but sustainable impact on business models, especially in the area of supporting services. On the other hand, completely new BM is already emerging through AI, which is only made possible using this technology. Such innovations have the strongest character on the strategic level for companies, in the sense that they can potentially be built on an increased or unique creation of value. Whether a resulting business model will have a disruptive nature cannot usually be assessed in advance but is a phenomenon that only occurs in the long term. The following diagram is intended to illustrate the previous results for the classification of the AI performance, described in the case studies. At this point, AIaaS and IaaS services are excluded, since they may be an essential component for the development of own AI applications. They are rather of secondary importance for the innovation potential concerning the implementation in the BM. Especially, the interface between activity and customer focus in a high (grand) level of innovation is of interest at this point. If both characteristics can be achieved by an AI application, it appears in the examples considered here as if this could lead to far-reaching changes in the BM. In theory, these changes have the potential to be disruptive (Fig. 3).

Finally, another assumption can be made regarding the disruptive nature of new business models in the field of AI. It is possible that AI-driven business models may have disruptive potential, provided that they can demonstrate a sufficiently strong focus on the activity and customer side in the business model. While the two cases presented here are merely intended to serve as an indicator for such an idea, further case studies as well as long-term studies about these business models are necessary.

\subsection{Derivation of the Dynamic Interaction and Resulting Strategies}

The question arises as to what insights entrepreneurs can draw from the findings derived here regarding the role of $\mathrm{AI}$ in the innovation of business models. First, it becomes clear that such a differentiation of AI applications as that made here is not a planning method for the development of AI within the company. Rather, this view opens a possibility to classify AI ideas and applications with respect to their influence on the business model using the presented matrix and roles. It can be 


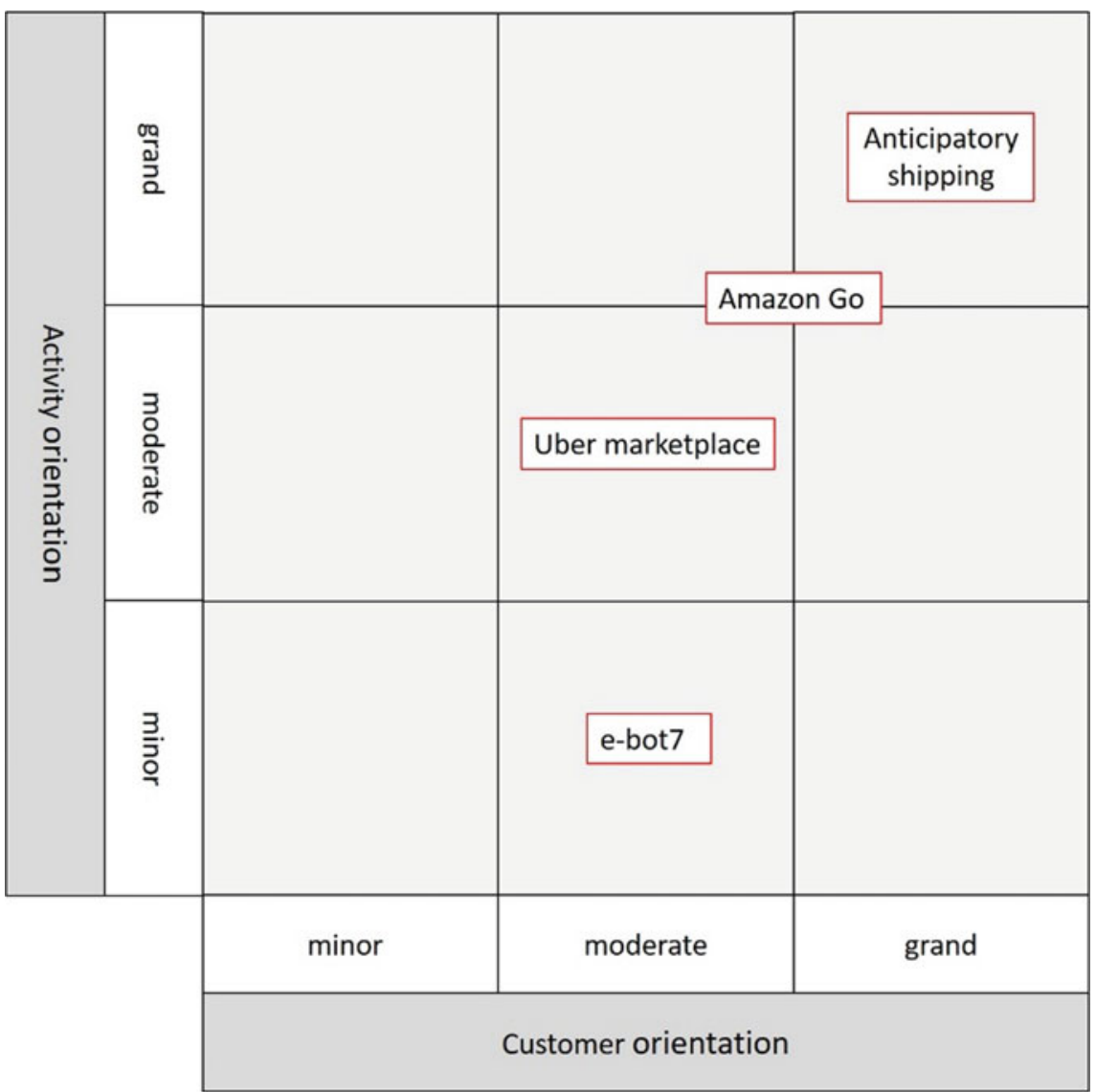

Fig. 3 Classification of presented AI applications cases

assumed that both assisting and supporting services will cause a rather incremental impact of innovation in the business model, whereas a driving force of $\mathrm{AI}$ in the business model would cause a profound change.

Furthermore, it is quite conceivable that different AI applications will coexist in the same enterprise. One such example is the case of Uber in a sense, which uses two of these types, Michelangelo and Uber Marketplace. However, while this only covers the lower end of the definition of the roles of AI, it is quite conceivable that a similar application is possible on the other end of the ladder. A resulting presumption would be the independence of the roles of AI within a company, in terms of their application. This would mean that companies could incorporate any form into their business model, independent of the other roles at hand. For planning the innovation of a company's business model, the awareness of independence and the influence of the respective AI performance are therefore central. An innovation of the business model would thus not be limited to one of the roles, but each role 
would be possible in any state of the business model over the course of strategic planning. For future research, the adaptation of planning procedures for business model innovation can therefore be an interesting aspect regarding the differentiation of AI roles. Especially the adaptation of the planning procedure to the needs of the companies regarding the own enhancement through AI is of interest. While it is conceivable that incremental innovations will only have a major impact when added up, it is to be expected that AI-driven business models cannot only represent completely new business models, but can also hold potential for deeper changes within the industry. This reduction allows for a deeper understanding of what the AI will contribute to the envisioned business model, while also solely focusing on the core change the AI does. Such a simplified view of the contribution of AI within the business model innovation is illustrated in the following figure, which shows an enhancement of the states (S) of the BM, independent of the AI applications used (Fig. 4).

Thus, the question arises on how an understanding of the role of AI-enhancement in business model innovation can help entrepreneurs to follow their own AI path. While the development of AI applications is becoming more and more dynamic, it is expected that the development of AI applications will become more and more rapidly in enterprises. This can be strengthened by the application of approaches such as minimum viable products or test-and-learn mentalities, which

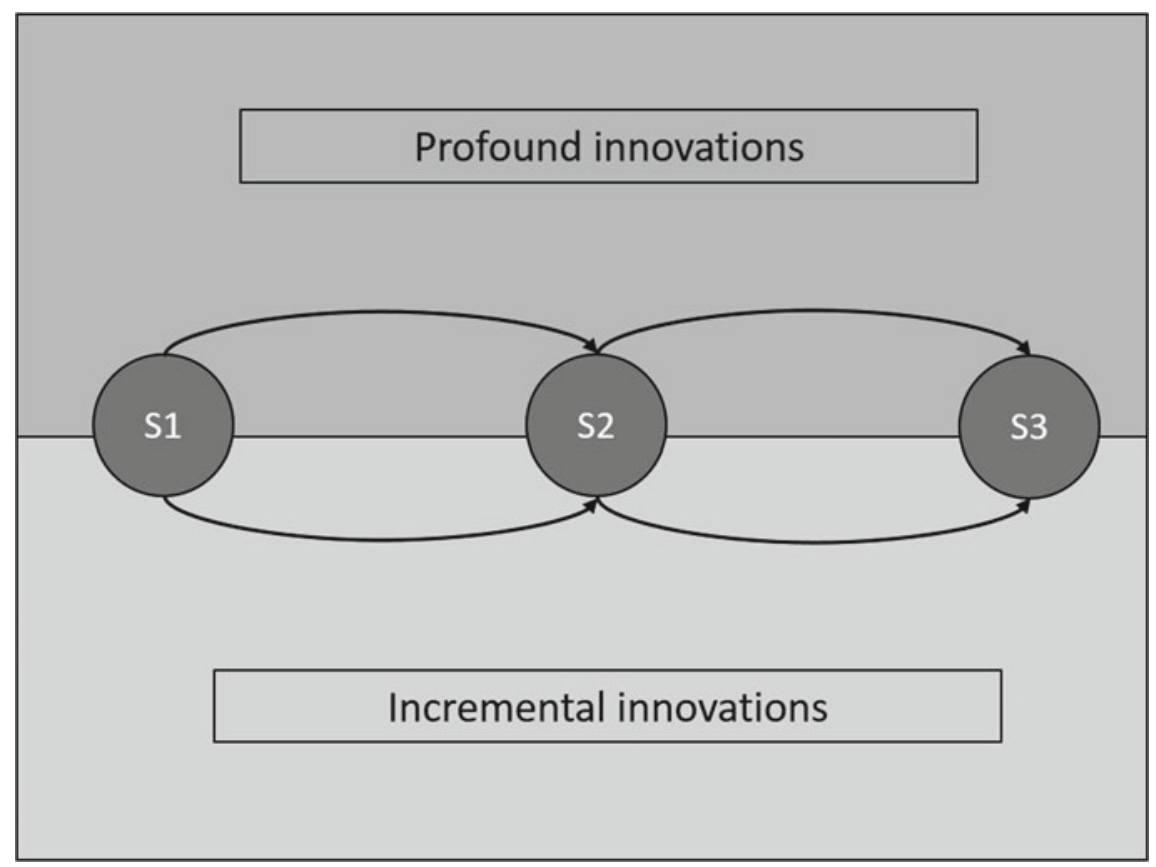

Fig. 4 Dynamic inventing states of BM 
allow to shorten the development time (cf. Fountaine et al. 2019, p. 5). A more dynamic view on business model enhancement could thus offer the option of not committing to long-term static plans, but rather to dynamized developments of AI according to the necessary role of AI in business model innovation. The proprietary AI path could thus be seen as a permanent innovation loop, modified by the selected AI performance.

In view of the different applications and their various effects, the question arises as to which derivations entrepreneurs can derive for their company in order to follow their own AI path. By means of the presented classification scheme, a derivation of general or standard strategies for entrepreneurs shall be derived. The previous studies of start-ups and incumbents show a possibility not only to prescribe the AI applications with respect to their extent in the classification scheme, but also to divide them into zones in order to imply a standardization strategy based on their strategic potential for the company. These standardization strategies should give the entrepreneur suggestions for action, based on the zones in which an AI application is located or has been identified by the user of the scheme. The following strategic implications could be fund by the investigations carried out in this chapter and are to be seen as suggestions for the own AI path of the entrepreneur.

\section{Outsourcing:}

Applications that have a (one-sided or two-sided) weak influence on the business model should be procured, if possible, through offers on the market, i.e. external providers. By outsourcing, the focus of AI's in-house development is directed to more influential applications and is released in their favour. Outsourcing should be chosen in particular when considering scarce resources.

\section{Incremental:}

Applications with a minor up to moderate influence on the business model can improve it incrementally. At this point, companies must weigh up between in-house development and outsourcing. Especially from a short-term perspective, incremental improvements to the business model are achievable in many ways and should therefore be constantly monitored.

\section{Profound:}

Applications have the potential to leave behind major changes in the business model. Such applications can give the company a competitive advantage and should therefore be the long-term goal with regard to the own AI path. Such AI solutions are usually not offered by external providers, and the focus should be on in-house development.

\section{Disruptor:}

Applications have the greatest potential to change entire industries in the long term and profoundly. The focus here is exclusively on in-house development and innovation of the own business model. 
These standardization strategies differ significantly in their potential for change at the business model level. In addition, it can be assumed that a distinction is made with regard to the performance of the application or the awareness of the competitors with regard to this application. Especially the differences between ordinary and unique or unchallengeable applications may be tempting, but this is again to be seen under the independence and simultaneous applicability of the applications. The previous distinction regarding supporting and driving AI services is also applicable here (Table 1).

These strategy fields for the applications are to be seen in dependence on the classifications schema presented before. The strategies do not appear as rigid boundaries within which one must think, but as blurring borders that show a flowing transition between the adjacent strategies and can thus be used depending on the respective situation and the assessment by the entrepreneur (Fig. 5).

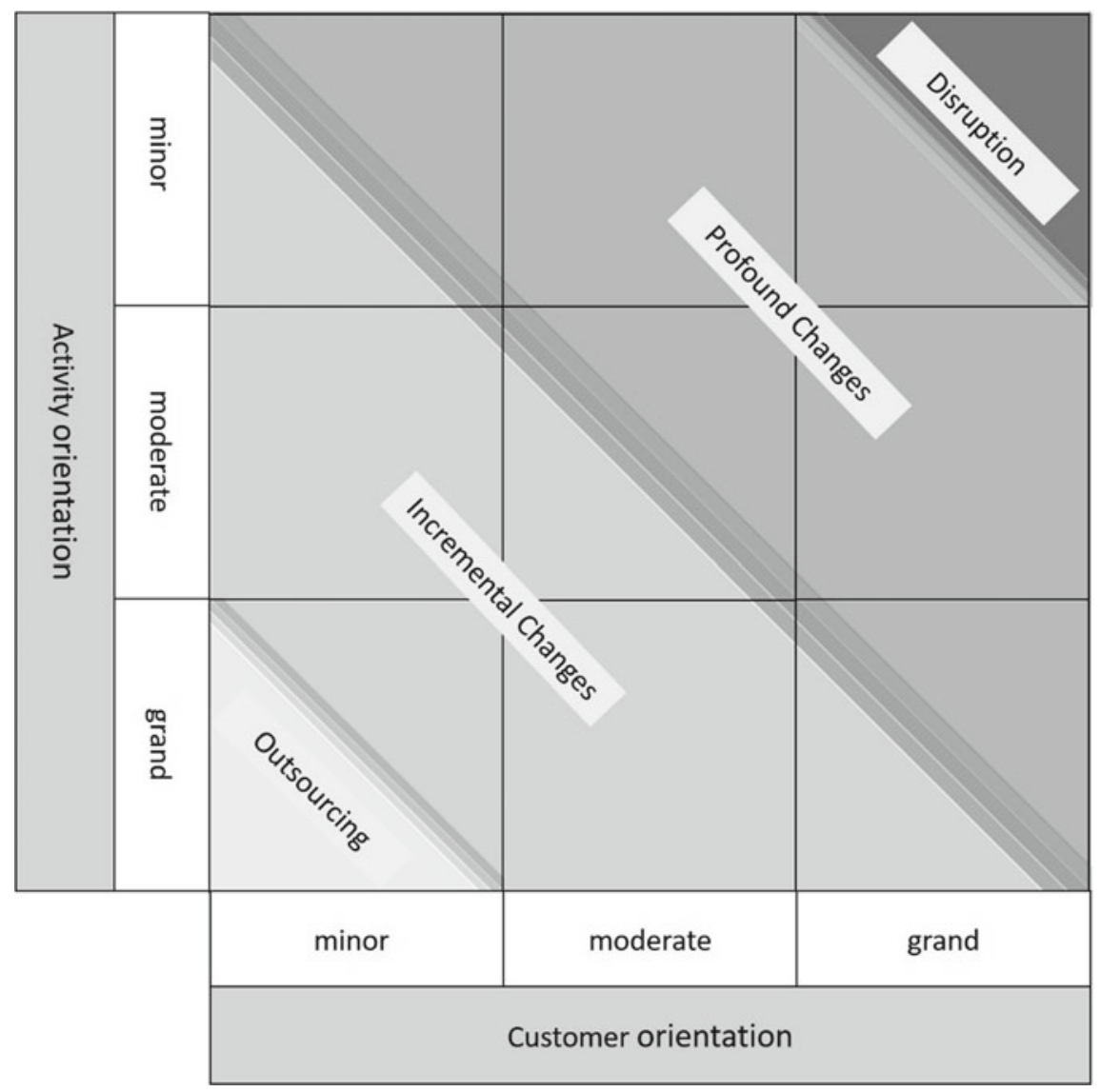

Fig. 5 Strategic zones for AI applications 


\section{Conclusion}

AI plays an increasingly important role for businesses. Researchers and entrepreneurs are becoming more and more aware of this topic, which is reflected in the number of research topics in this area.

In this chapter, we explored a strategic view of AI applications and their influence on the innovation of business models. The investigation of start-ups and incumbents opened the distinction of AI roles in business model innovation. The results showed that AI not only assists or supports but also has the potential to drive business models. Furthermore, a classification scheme was developed that allows to prescribe the impact of AI on the business model in terms of its inflow and orientation. This allows to identify interactions within the business model and to evaluate AI applications with respect to their innovation potential. In addition, the standardization strategies allow the entrepreneur to make proposals for action that can make his own AI path more accessible.

It is therefore essential that companies become aware of the diversity and range of AI applications and their potential. The AI roles, classification schemes and standardization strategies presented here are intended to provide a better understanding and to provide the entrepreneur with tools for strategic consideration.

New opportunities for entrepreneurs and researchers are related not only to the development of supporting applications, but also especially to the theoretical and practical design of AI-driven business models. The novelty of these business models can give rise to completely new business relationships, organizational structures and business processes that could lead to companies of a kind not seen before. Potential future research could therefore focus on the field of AI-driven enterprises, based on an AI-driven business model.

The challenges for entrepreneurs who want to pursue their own AI path are manifold. Data management, development costs and talents, operational and strategic changes are only a part of what can happen to companies now and in the future. Nevertheless, the AI path is already being taken by many companies, in the knowledge that this class of technology will change many areas of the economy forever. The advantage of going down the AI path as an entrepreneur is not only the elimination of a potential competitive disadvantage, but rather the possibility to develop and break new ground.

\section{Appendix}

See Table 2 . 
Table 2 References of AI Start-ups, (companies from: UnternehmerTUM GmbH 2020)

\begin{tabular}{|c|c|c|c|c|c|}
\hline Startup (KI) & Enterprise function & Service objective & Targeted BMC-Element & Al-function & Information at \\
\hline $12 x$ & Customer service & Customer comprehension & Segments & Al-supported & https://i2x.ai/ \\
\hline cognigy & Customer service & $\begin{array}{c}\text { Automated } \\
\text { commuincation }\end{array}$ & Channels & Al-supported & https://cognigy.com/ \\
\hline Botfriends & Customer service & $\begin{array}{l}\text { Chatbot/ Automated } \\
\text { communication }\end{array}$ & Channels & Al-supported & https://botfriends.de/en/ \\
\hline Kauz & Customer service & $\begin{array}{l}\text { Chatbot /automated } \\
\text { communication }\end{array}$ & Channels & Al-supported & https://kauz.net/en/ \\
\hline solvemate & Customer service & $\begin{array}{l}\text { Chatbot /automated } \\
\text { communication }\end{array}$ & Channels & Al-supported & $\begin{array}{c}\text { https://www.solvemate.q } \\
\text { om/en/ }\end{array}$ \\
\hline tywla & Customer service & $\begin{array}{l}\text { Chatbot /automated } \\
\text { communication }\end{array}$ & Channels & Al-supported & https://www.twyla.ai/ \\
\hline virtualQ & Customer service & $\begin{array}{l}\text { On-hold loop } \\
\text { improvements }\end{array}$ & Channels & Al-supported & https://virtualq.io/en/ \\
\hline Mercury & Customer service & $\begin{array}{l}\text { Chatbot /automated } \\
\text { communication }\end{array}$ & Channels & Al-supported & $\begin{array}{c}\text { https://www.mercury.ai/ } \\
\text { en/ }\end{array}$ \\
\hline Voixen & Customer service & Customer comprehension & Segments & Al-supported & $\begin{array}{c}\text { https: } / / \text { www.voixen.ai/e } \\
n\end{array}$ \\
\hline e-bot7 & Customer service & $\begin{array}{l}\text { Chatbot/automated } \\
\text { communication }\end{array}$ & Channels & Al-supported & https://e-bot7.co.uk/ \\
\hline parlamind & Customer service & $\begin{array}{c}\text { Automated } \\
\text { communication }\end{array}$ & Channels & Al-supported & $\begin{array}{c}\text { https://parlamind.com/e } \\
\mathrm{n} /\end{array}$ \\
\hline Fraugster & IT \& Security & Fraud detection & Cost structure & Al-supported & https://fraugster.com/ \\
\hline Dedrone & IT \& Security & Protection against drones & Resources & Al-assisted & $\begin{array}{c}\text { https://www.dedrone.co } \\
\mathrm{m} /\end{array}$ \\
\hline Xccelo & IT \& Security & Safety technology & Resources & Al-assisted & https://xccelo.com/en \\
\hline Neurocat & II \& Security & Al system security & Resources & Al-assisted & https://www.neurocat.ai \\
\hline Zeitgold & Finance \& Accounting & Automated Accounting & Cost structure & Al-supported & $\begin{array}{c}\text { https://www.zeitgold.co } \\
\text { m/zlang=en }\end{array}$ \\
\hline candis & Finance \& Accounting & Automated Accounting & Cost structure & Al-supported & https://www.candis.io/ \\
\hline $\operatorname{taxy}$ & Finance \& Accounting & Automated taxation & Cost structure & Al-assisted & https://www.taxy.io/ \\
\hline troy & Finance \& Accounting & $\begin{array}{c}\text { Debt collection } \\
\text { management }\end{array}$ & Cost structure & Al-supported & \begin{tabular}{|c|} 
https://www.troy- \\
bleiben.de/en/kategorie/ \\
general/
\end{tabular} \\
\hline Bunch & $H \& R$ & Manager management & Cost structure & Al-assisted & https://bunch.ai/ \\
\hline Joblift & $H \& R$ & $\begin{array}{l}\text { Job platform } \\
\text { management }\end{array}$ & Cost structure & Al-supported & https://joblift.co.uk/ \\
\hline jobpal & $H \& R$ & $\begin{array}{l}\text { Chatbot for recruiting } \\
\text { interviews }\end{array}$ & Cost Structure & Al-asissted & https://jobpal.ai/en/ \\
\hline Mindmatch & $H \& R$ & Job ad distribution & Cost structure & Al-supported & https://mindmatch.ai/ \\
\hline retorio & $H \& R$ & Al video recruiting & Cost structure & Al-assisted & https://www.retorio.com \\
\hline rfrnz & Legal & $\begin{array}{c}\text { Automated contract } \\
\text { analysis }\end{array}$ & Cost structure & Al-assisted & https://www.rfrnz.com/ \\
\hline synergist & Legal & $\begin{array}{l}\text { Automated recurring } \\
\text { contracts }\end{array}$ & Cost structure & Al-assisted & https://synergist.io/ \\
\hline risk methods & $\begin{array}{l}\text { Supply chain } \\
\text { management }\end{array}$ & $\begin{array}{c}\text { Riskmanagement of } \\
\text { supply chains }\end{array}$ & Cost structure & Ai-assisted & $\begin{array}{c}\text { https://www.riskmethod } \\
\text { s.net/ }\end{array}$ \\
\hline kinexion & $\begin{array}{l}\text { Supply chain } \\
\text { management }\end{array}$ & Tracking of goods & Activites & Al-assisted & https://kinexon.com/de \\
\hline intranav & $\begin{array}{l}\text { Supply chain } \\
\text { management }\end{array}$ & 3D-localization of goods & Activities & Al-assisted & https://intranav.com/ \\
\hline CrossEngage & Sales \& Marketing & $\begin{array}{l}\text { Al Multi-Channel } \\
\text { Marketing } \\
\end{array}$ & Channels & Al-supported & \begin{tabular}{|c|} 
https://www.crossengag \\
e.io/
\end{tabular} \\
\hline $2 \mathrm{Txt}$ & Sales \& Marketing & $\begin{array}{l}\text { Text generation for } \\
\text { product descriptions }\end{array}$ & Channels & Al-assisted & https://2txt.de/ \\
\hline admetrics & Sales \& Marketing & $\begin{array}{c}\text { Al marketing } \\
\text { experimentation }\end{array}$ & Channels & Al-supported & $\begin{array}{c}\text { https://www.admetrics.i } \\
\text { o/en/start/ }\end{array}$ \\
\hline Upcue & Sales \& Marketing & Al sales assistant & Channels & Al-supported & https://www.upcue.com \\
\hline Blackout & Sales \& Marketing & conversional Al tools & Channels & Al-supported & https://blackout.ai/ \\
\hline Network insight & Sales \& Marketing & Cloud infrastructure & Key ressources & Al-assisted & $\begin{array}{c}\text { https://www.vmware.co } \\
\text { m/de/products/vrealize- } \\
\text { network-insight.html }\end{array}$ \\
\hline Sensape & Sales \& Marketing & $\begin{array}{l}\text { Interactive Marketing } \\
\text { (VR-based) }\end{array}$ & Channels & Al-supported & $\begin{array}{c}\text { https://www.sensape.co } \\
\text { m/en/ }\end{array}$ \\
\hline Simplaex & Sales \& Marketing & User targeting & Segments & Al-supported & $\begin{array}{c}\text { https://www.simplaex.co } \\
\mathrm{m} /\end{array}$ \\
\hline
\end{tabular}




\begin{tabular}{|c|c|c|c|c|c|}
\hline Styla & Sales \& Marketing & Al content creation & Channels & Al-assisted & https://www.styla.com/ \\
\hline Adtriba & Sales \& Marketing & $\begin{array}{l}\text { Cross-channel } \\
\text { management }\end{array}$ & Channels & Al-supported & $\begin{array}{c}\text { https://www.adtriba.com } \\
/\end{array}$ \\
\hline Attention Insight & Sales \& Marketing & Al design analytics & Channels & Al-assisted & $\begin{array}{c}\text { https://www.attentionins } \\
\text { ight.com/ }\end{array}$ \\
\hline Ubermetrics & Sales \& Marketing & $\begin{array}{l}\text { Al multichannel } \\
\text { marketing }\end{array}$ & Channels & Al-supported & $\begin{array}{c}\text { https://www.ubermetrics } \\
\text {-technologies.com/ }\end{array}$ \\
\hline Wonderwerk & Sales \& Marketing & Al sales training & Channels & Al-assisted & $\begin{array}{c}\text { https://www.wonderwer } \\
\text { k.co/ }\end{array}$ \\
\hline Scoutbee & Procurement & $\begin{array}{l}\text { Procurement Database } \\
\text { für transparency }\end{array}$ & Activities & Al-assisted & https://scoutbee.com/ \\
\hline Pricefx & Sales \& Pricing & Pricemanagement & Activities & Al-assisted & https://www.pricefx.com \\
\hline Iplytics & $\begin{array}{l}\text { Market Data \& } \\
\text { Information }\end{array}$ & $\begin{array}{l}\text { Market data } \\
\text { management }\end{array}$ & Activities & Ai-assisted & $\begin{array}{c}\text { https: //www.iplytics.com } \\
/\end{array}$ \\
\hline Mapegy & $\begin{array}{c}\text { Market Data \& } \\
\text { Information }\end{array}$ & $\begin{array}{c}\text { Innovation information } \\
\text { management }\end{array}$ & Resources & Al-assisted & $\begin{array}{c}\text { https: //www.mapegy.co } \\
\mathrm{m} /\end{array}$ \\
\hline Vencortex & Decison Making & Design augmentation & Resources & Al-assisted & $\begin{array}{c}\text { https://www.vencortex.c } \\
\text { om/ }\end{array}$ \\
\hline Neuroflash & Marketing & Content Creation & Channels & Al-assisted & https://neuro-flash.com/ \\
\hline
\end{tabular}

\section{References}

Agrawal, A., Gans, J., \& Goldfarb, A. (2018). Prediction machines. The simple economics of artificial intelligence. Boston, Massachusetts: Harvard Business Review Press.

Amazon.com Inc. (2020a). Amazon Web Services (AWS)—Cloud Computing Services. With assistance of. Available online at https://aws.amazon.com/?nc1=h_ls. Updated on 2/19/2020, checked on 3/12/2020.

Amazon.com Inc. (2020b). Amazon.com: Amazon Go. Available online at https://www.amazon. com $/ \mathrm{b}$ ?language $=$ en_US\&node $=16008589011 \&$ tag $=$ bisafetynet -20 . Updated on $3 / 12 / 2020$, checked on 3/12/2020.

Clickatell Inc. (2020). Will Amazon Go's AI put an end to thousands of retail jobs?-Clickatell. Available online at https://www.kungfu.ai/wp-content/uploads/2019/07/HBR-Building-the-AIPowered-Org.pdf. Updated on 3/12/2020, checked on 3/12/2020.

DIA Group B.V. (2020). e-bot7: Artificial Intelligence for Customer Service|Digital Insurance Agenda|Accelerate Innovation in Insurance. Available online at https://www.digitalinsurance agenda.com/304/e-bot7-artificial-intelligence-for-customer-service/. Updated on 3/10/2020, checked on 3/10/2020.

e-bot7. (2020a). About Us $\mid$ We are building the next generation AI-based communication platform. Available online at https://e-bot7.co.uk/about-us/. Updated on 3/10/2020, checked on $3 / 10 / 2020$.

e-bot7. (2020b). Customer service use cases. Available online at https://e-bot7.de/kundenservice/. Updated on 3/2/2020, checked on 3/2/2020.

Google Patents. (2012). US8615473B2-Method and system for anticipatory package shippingGoogle Patents. Available online at https://patents.google.com/patent/US8615473B2/en. Updated on 3/8/2020, checked on 3/8/2020.

Hermann, J. (2017). Meet Michelangelo: uber's machine learning platform. Available online at https://eng.uber.com/michelangelo-machine-learning-platform/. Updated on 3/12/2020, checked on 3/12/2020.

Iansiti, M., Lakhani, K.R. (2020). Competing in the age of AI. Strategy and leadership when algorithms and networks run the world. Boston, MA: Harvard Business Review Press.

Intel Corporation. (2020). Examples of artificial intelligence in everyday life. Available online at https://www.intel.de/content/www/de/de/analytics/artificial-intelligence/ai-in-your-pocketinfographic.html. Updated on 3/7/2020, checked on 3/7/2020. 
Kreutzer, R., Sirrenberg, M. (2020). Understanding artificial intelligence. Fundamentals, use cases and methods for a corporate AI journey. Cham: Springer (Management for professionals).

Lee, J., Suh, T., Roy, D., \& Baucus, M. (2019). Emerging technology and business model innovation: The case of artificial intelligence. JOItmC, 5(3), 44. https://doi.org/10.3390/ joitmc5030044.

Legg, S., Hutter, M. (2007). A collection of definitions of intelligence. In Frontiers in Artificial Intelligence and Applications. Available online at http://arxiv.org/pdf/0706.3639v1.

Lomas, N. (2014). Amazon patents "Anticipatory" Shipping - To start sending stuff before you've bought it-TechCrunch. Available online at https://techcrunch.com/2014/01/18/amazon-preships/. Updated on 3/8/2020, checked on 3/8/2020.

Marr, B., Ward, M. (2019). Artificial intelligence in practice. How 50 successful companies used artificial intelligence to solve problems. Chichester, West Sussex: Wiley.

Metelskaia, I., Ignatyeva, O., Denef, S., Samsonowa, T. (2018). A business model template for AI solutions. In L. Moutinho, X.-S. Yang (Eds.), Proceedings of the International Conference on Intelligent Science and Technology - ICIST '18. The International Conference. London, United Kingdom (pp. 35-41), 30.06.2018-02.07.2018. New York, USA: ACM Press.

On Marketing. (2014). Why Amazon's anticipatory shipping is pure genius. Available online at https://www.forbes.com/sites/onmarketing/2014/01/28/why-amazons-anticipatory-shipping-ispure-genius/\#9f115b84605e. Updated on 3/8/2020, checked on 3/8/2020.

Osterwalder, A., Pigneur, Y. (2010). Business model generation. A handbook for visionaries, game changers, and challengers. 2. print. Toronto: Flash Reprod.

Rao, A. (2017). A strategist's guide to artificial intelligence. As the conceptual side of computer science becomes practical and relevant to business, companies must decide what type of AI role they should play. In strategy + business (87), pp. 1-12. Checked on 4/14/2020.

Siggelkow, N. (2007). Persuasion with case studies. AMJ, 50(1), 20-24. https://doi.org/10.5465/ amj.2007.24160882.

Skilton, M., Hovsepian, F. (2018). The 4th Industrial Revolution. Responding to the Impact of Artificial Intelligence on Business. Cham: Springer International Publishing.

Uber. (2020). Marketplace| Uber. Available online at https://kthexecutiveschool.se/wp-content/ uploads/2018/10/sb87_17210_Strategists_Guide_to_Artificial_Intelligence.pdf. Updated on $3 / 13 / 2020$, checked on 3/13/2020.

UnternehmerTUM GmbH. (2020). Startup Landscape 2020-AppliedAI. Available online at https://appliedai.de/startup-landscape-2020/. Updated on 3/17/2020, checked on 3/17/2020.

Open Access This chapter is licensed under the terms of the Creative Commons Attribution 4.0 International License (http://creativecommons.org/licenses/by/4.0/), which permits use, sharing, adaptation, distribution and reproduction in any medium or format, as long as you give appropriate credit to the original author(s) and the source, provide a link to the Creative Commons license and indicate if changes were made.

The images or other third party material in this chapter are included in the chapter's Creative Commons license, unless indicated otherwise in a credit line to the material. If material is not included in the chapter's Creative Commons license and your intended use is not permitted by statutory regulation or exceeds the permitted use, you will need to obtain permission directly from the copyright holder.

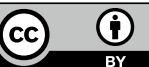

